RESEARCH ARTICLE

\title{
Deliberative Quality and Expertise: Uses of Evidence in Citizens' Juries on Wind Farms
}

\author{
Sara A. Mehltretter Drury*, Stephen Elstub†, Oliver Escobar and Jennifer J. Roberts ${ }^{\S}$
}

When addressing socioscientific wicked problems, there is a need to negotiate across and through multiple modes of evidence, particularly technical expertise and local knowledge. Democratic innovations, such as deliberative citizens' juries, have been proposed as a means of managing these tensions and as a way of creating representative, fairer decision making. But there are questions around participatory processes, the utilization of expertise and deliberative quality. This article considers forms of argumentation in the 2013-2014 'Citizens' juries on wind farm development in Scotland'. Through a critical-interpretive research methodology drawing on rhetoric and argumentation, we demonstrate that arguments relating to the topoi of the environment and health functioned as de facto reasoning, whereas arguments using social scientific evidence around economics more prominently interacted with local knowledge. The findings offer implications for process design to improve and promote deliberative quality in mini-publics and other forms of participatory engagement on socioscientific issues.

Keywords: argumentation; deliberation; expertise; mini-publics; reasoning; rhetoric

\section{Introduction}

Political life is riddled with tensions between technical knowledge and knowledge gained from lived, localized experiences. The public framing and discussion of socioscientific issues calls forth towards this tension. They require negotiation across and through multiple claims and forms of evidence, from technical and scientific to personal and moral (Gastil 2017; Goodnight 2005). Democratic innovations, such as deliberative minipublics, have been proposed as a means of managing these tensions and to produce better-informed and fairer decision-making (Elstub 2014; Escobar \& Elstub 2017).

Deliberative mini-publics have been developed, primarily, to promote reified deliberative norms in practice (Böker \& Elstub 2015). The closer discussions in mini-publics get to approximating these norms, the better the deliberative quality. The key norms of deliberative quality include reason giving, respect, listening and openmindedness. Although there is a good degree of research on deliberative quality in mini-publics (Caluwaerts \& Reuchamps 2014; Gerber 2015; Gerber et al. 2016; Himmelroos 2017; Elstub \& Pomatto 2018; Karpowitz,

\footnotetext{
* Department of Rhetoric, Wabash College, Crawfordsville, US

+ Department of Politics, Newcastle University, Newcastle, UK

Edinburgh Futures Institute and School of Social and Political Science, University of Edinburgh, Edinburgh, UK

$\S$ Department of Civil and Environmental Engineering, University of Strathclyde, Glasgow, UK

Corresponding author: Sara A. Mehltretter Drury

(drurys@wabash.edu)
}

Mendelberg \& Shaker 2012; Pedrini 2014; Siu 2017), there remain questions about the roles of expert witnesses and types of evidence used within deliberative processes. This is surprising as experts are integral to the mini-public process design and crucial to providing information that enables the participants to engage in meaningful deliberation on the issue under consideration. Research suggests that this information is pivotal to participants' individual preferences and collective recommendations at the end of the process (Goodin \& Niemeyer 2003). Moreover, experts may share different types of evidence when compared to lay participants in deliberative mini-publics.

Attaining deliberative quality does not necessarily mean a reliance on either expertise or experiential knowledge, but rather calls for a more flexible combination of different forms of argumentation. Consequently, there remains a need to further analyse the opportunities and challenges of citizen deliberation around socioscientific issues. In particular, rhetoric and argumentation studies can offer insights into how expertise and experiential knowledge function within deliberative mini-publics. Arguments from technical expertise are examples of argumentum ad verecundiam, or 'appeal to authority' (Walton 1997; see also Woods \& Walton 1974). Such arguments are located in what Goodnight (1982: 220) refers to as the 'technical sphere', a mode of discourse relying on 'specialized forms of reasoning' with 'more limited rules of evidence, presentation, and judgment [sic]' found in expert interlocutors. In cases of weaker or fallacious argumentum ad verecundiam, an argument is made through an appeal to authority that assumes that the 
speaker's ideas or reasoning are absolute and 'not open to challenge' (Walton 1997: 252). This form of reasoning is at odds with deliberative democracy, and its requirement for rational and public justification. A strength of deliberative mini-publics is that they can enable a reasoning process that engages technical expertise and what Fischer (2000: 194-195) has labelled 'local knowledge', an expertise found in day-to-day understandings of issues, developed over time, particular to the local culture and context. This localized reasoning can be slightly harder to define than technical reasoning, as it draws from a number of evidentiary sources and perspectives that can be embodied by deliberative participants, including personal experiences, interests and local contexts, as well as their own professional/expert perspectives.

There is a need, therefore, to further understand the rhetorical-argumentative components of expertise and engagement with respect to deliberative quality. Deliberative issues addressed in a local context invite arguments emerging from multiple perspectives, including technical expertise, professional expertise and local knowledge of lived experiences. The interplay of different forms of reasoning can function within a public sphere of argument, or can isolate reasoning within the personal or technical spheres. Goodnight (1982: 220) explained this complexity of public deliberation, noting that "[i]n the world of arguers, any particular argumentative artifact can be taken to be grounded in any one of the spheres [technical, personal, or public] or a combinatory relationship'. Studying the rhetorical dynamics of expertise and experience can therefore identify opportunities and challenges for robust public reasoning, with implications for the future design of deliberative mini-publics and participatory, deliberative innovations.

The 'Citizens' juries on wind farm development in Scotland' project offers an opportunity to examine whether and how evidence from expertise and experience impact deliberative quality in mini-publics. This research project organized and held three citizens' juries in Scotland involving 47 participants (Roberts \& Escobar 2015). The three locations were selected according to their proximity to active or proposed wind farms while keeping other factors such as population size comparable (see Table 1). In each location, a group of 15 to 18 local citizens were charged with answering the question "What should be the key principles for deciding about wind farm development, and why?' The jurors were supported to achieve their task by a structured and facilitated 2-day process held on Saturdays, 2 to 3 weeks apart in the period November 2013 to February 2014. Day 1 constituted an 'information phase', where witnesses gave evidence and competing advocacy on wind energy and onshore wind farms. This was followed on day 2 by a 'deliberation phase' during which the group considered, discussed and decided their recommendations for key principles to guide onshore wind farm development in Scotland. Details of the project, the process and outcomes are reported in Roberts and Escobar (2015).

Using transcripts from the citizens' juries on wind farm development, this article examines how topoi of expertise and experiential knowledge function in deliberative argument. Our analysis adopts an interpretive research methodology (Ercan, Hendriks \& Boswell 2017) of applied rhetorical criticism using theories of argumentation (Condit \& Bates 2009; see also Asen et al. 2011). In so doing,

Table 1: Locations and summary characteristics for the three citizens' juries on wind farms held in Scotland between November 2013 and February 2014.

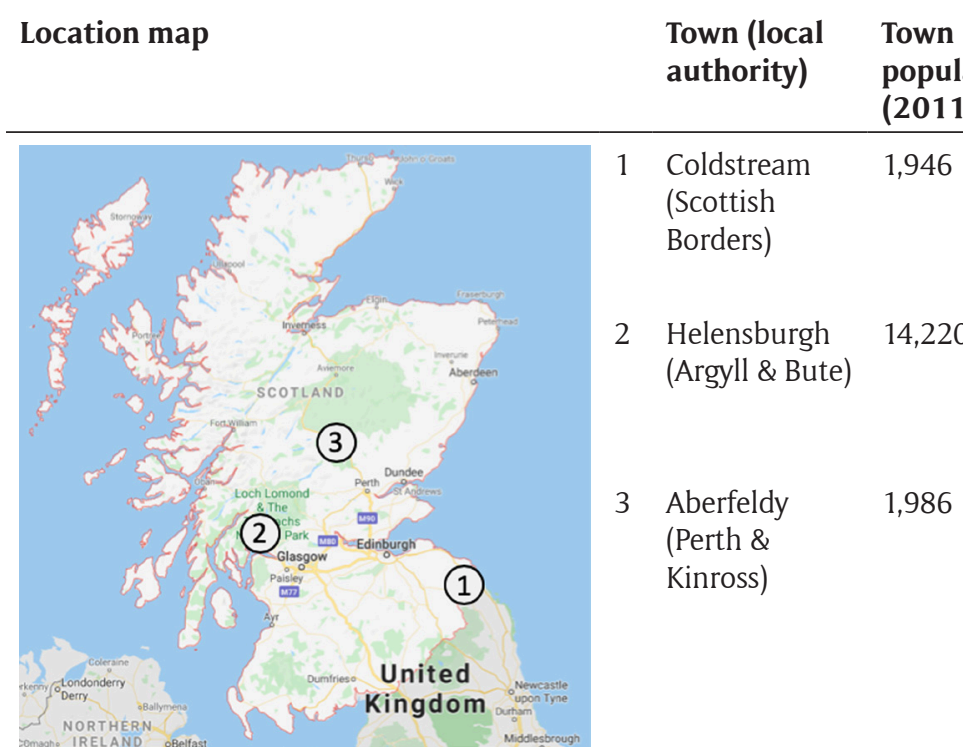

Proximity to wind
farms (in 2013)

No wind farms nearby. No active wind farm planning applications nearby

No wind farms nearby. A proposal for a small local wind farm was in early planning stages

Two large wind farms operating nearby

\section{Number of participants}

\section{5}

14

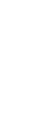

Map of mainland Scotland showing the location of the three towns where citizens' juries were held in 2013-2014. (Adapted from Google Maps, 2020) 
the analysis identifies prominent forms of arguments relating to expertise, and considers how they interact and function in decision-making. Arguments using evidence related to natural science (in this case, the environment and health), prominently functioned as de facto reasoning, whereas arguments using social scientific evidence (in this case, primarily economics) functioned to bring together expertise and experience. We conclude that the wind farm citizens' juries fostered an argumentation exchange that enabled deliberators to focus deeply on the values articulated through deliberation. The article proceeds in five sections. We first review the literature on scientific evidence, argumentation and deliberative quality in minipublics. Then, section 2 gives an overview of our case study, followed by an outline of the methodology. Section 4 presents the findings, before concluding with reflections on their implications.

\section{Socioscientific Wicked Problems, Argumentation and Deliberative Quality}

Many of the most pressing scientific problems facing the world today are 'wicked problems'. Such problems are, in their nature, both scientific and social, often being characterized as 'socioscientific issues' or SSI (Bauer, Allum \& Miller 2007; Gross 1994). Although science is used to grappling with difficult challenges, these challenges can still be characterized as 'tame or benign' due to the clarity of mission, experimental method to determine a solution, as well as the ability to know if the problem has been solved (Rittel \& Webber 1973: 160). In contrast, wicked problems are fraught with complexity, as they typically are hard to define, involve multiple stakeholders and actors, and cannot be addressed through trial and error (Head 2008; Rittel \& Webber 1973). Wicked problems around scientific concerns involve sociocultural factors as well as technical ones. Addressing wicked problems entails managing conflicting issues, values and impacts, rather than merely identifying solutions. The constraints of wicked problems are felt within scientific public problems such as climate change, environmental governance and sustainability. Some socioscientific wicked problems even rise to the level of 'super' wicked problems, with heightened concerns around four features: 'time is running out; those who cause the problem also seek to provide a solution; the central authority needed to address them is weak or nonexistent; and irrational discounting occurs that pushes responses into the future' (Levin et al. 2012: 124).

One avenue for addressing these sorts of socioscientific wicked problems is through participatory governance comprising of public deliberation processes (Dietz 2013; Dryzek, 2014; Macnaughten, Kearnes \& Wynne 2005; Von Wienterfeldt 2013). Public deliberation encourages the exchange and working through of perspectives, value hierarchies, benefits and tradeoffs to prioritize actions (Nabatchi 2012). As such, it offers an opportunity to engage challenging public issues and determine steps forward. Deliberation can give citizens a chance to learn about the topic at hand, express their perspectives, consider different options, weigh benefits and tradeoffs and ultimately, choose a pathway that promotes common goods (Burkhalter, Gastil \& Kelshaw 2002; Mansbridge et al. 2006).

Yet creating an interplay of reasoning forms can be challenging, because engaging socioscientific issues involves connecting-or perhaps, in some cases, re-connecting and repairing-perceived and real divides between scientific experts and the public (Bohman 1999; Fischer 2000; Renn 2004). In these types of discursive fields, public deliberation processes can be designed to encourage the consideration of professional expertise as well as personal and local experience. Studying the argumentation of such areas lends insight into how citizens communicate with one another during deliberation (Adams 2014; Asen \& Gent 2019; Asen et al. 2013; Steffensmeier \& Schenck-Hamlin 2008). Arguments from expertise, or argumentum ad verecundiam, are defined as appeals to authority, which Woods and Walton (1974: 136) note are arguments that 'give preferential credibility to the reasoned judgment of an expert over the judgment of a layman'. The term argumentum ad verecundiam draws from John Locke's work on reasonable exchange; argumentation scholars have used the term to theorize how expertise can have both valid and fallacious reasoning in discourse and in public deliberation (Goodwin 2011; Walton 2008). Such appeals must be evaluated through their contexts, separating 'special position claims and claims from expertise', which requires assessing the 'aspects or elements of expert opinion which make it expert, not just the view of an expert' (Woods \& Walton 1974: 137, emphasis in original). Even while recognizing specific conditions for valid argumentum ad verecundiam, Woods and Walton (1974) postulate that expertise might best be validated through 'dialectical' arrangements, wherein a second interlocutor group responds to the claims made by the expert(s). This contextualizes technical argumentation within a public sphere of argument (Goodnight 1982).

While expertise is an important component of understanding public issues, without dialectical evaluation of argumentum ad verecundiam, an argument from expertise may devolve into an argument from the ethos of privileged position, de facto rather than reasoned judgement. In the public deliberation of socioscientific issues, expertise can be re-engaged and examined within a framework of local knowledge (Fischer 2000), prompting a consideration of relevance and validity. Even the interjection of interest-based reasoning can be a valid challenge to de facto expertise, particularly when done to re-examine expertise within a public, rather than expert, context (Zenker 2011).

The expression of tension between argumentum ad verecundiam and localized engagement in public issues has been noted by scholars of argumentation. Asen et al. (2011: 209) examined school board deliberations in Wisconsin and determined that citizens acting as elected school board members used 'research' rhetorically to suggest an appeal to authority and therefore a rationale for decision-making, but noted that when two or more parties used research that had conflicting conclusions, this created a 'lack of resolution' around deliberative questions. Majdik and Keith (2011: 371-372) have criticized appeals 
to expertise as 'in contrast to liberal democratic values' because of its function of silencing citizens. They advocate a rehabilitation of expertise to orient more towards localized norms and understanding. Yet Levasseur and Carlin's (2001) research on public deliberation found that citizens are likely to rely on egocentric argumentation when discussing public issues, although Drury et al. (2016) note that training in public deliberation may mitigate this tendency and Escobar (2014: 171-176) shows how facilitators can enable participants to shift from private to public reasoning. Furthermore, when deliberations are designed with opportunities for engagement and questioning of technical expertise, participants then incorporate evidence from the technical sphere into a more public reasoning, bringing expertise alongside local engagement and knowledge (Gastil \& Knobloch 2020; Roberts et al. 2020; Sprain, Carcasson \& Merolla 2014).

Studying mini-publics from an argumentation framework will help address gaps in our understanding of how communication influences the process of information flow, reasoning and judgement. Previous research on deliberative quality indicates that mini-publics provide a favourable environment for participants to deliberate to a high standard on complex issues, although improvements could be made with respect to reason giving (Elstub \& Pomatto 2018). This finding is supported by comparisons of deliberative quality between citizens and professional politicians. The latter are inferior with respect to all aspects of deliberation other than justification (Pedrini 2014) and also references to the common good (Himmelroos 2017). It is unclear though whether deliberative quality affects opinion change in mini-publics (Caluwaerts \& Reuchamps 2014); also, existing research has just begun to consider the influence of expert witnesses, and types of evidence that they provide, on deliberative quality (Gastil \& Knobloch 2020; Lukianova et al. 2019; Roberts et al. 2020). We seek to further this research on argumentation and deliberative quality through the use of a case study of a series of citizens' juries on onshore wind farms.

\section{Case Study: Citizens' Juries on Wind Farm Development in Scotland}

The 'Citizens' juries on wind farm development in Scotland' case study was a research project ${ }^{1}$ that aimed to trial the citizens' jury format and its applicability to a complex policy issue (onshore wind farm development in Scotland), and to provide insight into how citizens think about the issue and why. The process was not designed to feed directly into official decision making, but to inform decision-makers about deliberative forms of public engagement. The project provided the groundwork for the current wave of mini-publics in Scotland. ${ }^{2}$ All research for the project complied with the Ethics Policy and Procedure of the School of Social and Political Science at the University of Edinburgh. Informed written consent was obtained from all research participants throughout the project.

A Stewarding Board oversaw the project to ensure the legitimacy of the exercise amongst stakeholders. The Board decided on aspects of the project, including the locations of the juries and the list of prospective witnesses for the organisers to approach. The Stewarding Board also designed the jurors' task, which was articulated as follows: 'There are strong views on wind farms in Scotland, with some people being strongly opposed, others being strongly in favour and a range of opinions in between. What should be the key principles for deciding about wind farm development in Scotland, and why?'.

The project held three citizens' juries in the period November 2013 to February 2014 in three locations across Scotland: Coldstream, Helensburgh and Aberfeldy. These are similarly sized towns, each with a different proximity to onshore wind farms: Coldstream did neither have a wind farm nearby, nor one proposed; Helensburgh had a proposed wind farm development nearby and Aberfeldy had existing large wind farms nearby. Key characteristics and locations of each citizens' jury are summarized in Table 1.

Each jury comprised between 15 and 18 participants, with 47 people participating in total. The jurors were recruited face-to-face (on-street and by household) by the opinion research company Ipsos Mori and selected to reflect a cross-section of the citizenry demographically as well as discursively (e.g. range of views on wind farms). The jury topic remained unknown to the participants before the event to minimize self-selection (this was possible by including a broad range of topics in the recruitment questionnaire).

Each citizen jury tackled the same issue via the same 2-day format.

Each citizens' jury was held over two Saturdays, either 2 or 3 weeks apart. Saturdays were selected to maximize attendance, and the events were held in locations that were central to the local community, such as the village hall. Participants were remunerated for their participation at the end of each day to lower barriers to participation.

The first jury day was largely dedicated to evidencesharing, and is referred to as the 'information phase'. There were three themed sessions over the course of the day: energy and climate change, wind energy and wind farms. In each, jurors explored the theme by hearing a short presentation in plenary from a speaker, referred to as 'expert witness', then working in small groups to develop and prioritize questions that they then posed to the witnesses in a plenary question and answer session. A summary of the session structure, the content of the witnesses' talks and the questions posed by the jurors are presented in Table 2 . In total, five witnesses provided testimony during the first day. The speakers were identified by the Stewarding Board and approached by the organizers. While the organizers aimed for the same witnesses to participate in each jury, this proved difficult owing to witness availability. Due to substitutions, seven experts participated in total, including three representatives from universities, two from non-governmental organizations and two from trade bodies.

In addition to the information shared during the witness sessions on the first Saturday, the witnesses provided written responses via the organizers to jurors' outstanding questions in the interim weeks before the second Saturday. 
Table 2: Summary of the three evidence-sharing sessions (topics, structure and content) during the first Saturday of the jury, the 'information session'.

\section{Session 1: Energy and Climate Change}

Jurors heard from one witness, who was asked to present an impartial introduction to energy and the environment. The same witness fulfilled this role for all three juries.

The session began with a video about energy and climate change, followed by a presentation including historical developments (emissions and the industrial revolution), and key concepts and terminology around the generation and use of energy and electricity, and the linkage between energy and climate change.

The jurors' questions to this witness covered numerous themes, including climate concerns, energy alternatives and energy needs and consumption.

\section{Session 2: Wind Energy}

Jurors heard two opposing views on onshore wind energy. The witness speaking order was determined by coin-toss at the session start.

One witness made the case for wind power. The presentation addressed questions such as 'how does wind energy work?' and 'is wind energy efficient?', and explained concepts necessary to understand these answers, such as base load and intermittency. The value of the renewable energy sector in Scotland was presented in terms of jobs, skills and the Scottish economy. The same witness fulfilled this role for all three juries.

The other witness presented the case against wind power, highlighting inefficiencies and unreliability (including lack of energy storage), as well as the range of environmental and human health impacts and the profiteering of landowners and energy companies (with mention of government subsidies for renewable energy). It was argued that wind farms present no benefit to local communities, and examples were given where local residents opposed a wind farm development but were overridden by planning decisions. This role was fulfilled by two people (one for one jury, another for two juries). One speaker also critiqued the claims around job creation and value to Scotland's economy.

The jurors' questions to the witnesses covered numerous themes, but all three juries asked questions around who benefits from wind power development and who makes the decisions, as well as negative impacts of wind farms and alternative energy sources.

\section{Session 3: Wind Farms}

Jurors heard two opposing views on onshore wind farms. The witness speaking order was determined by coin-toss at the session start.

One witness made the case for wind farms, presenting the benefits that wind farms bring to communities (from co-ownership models to community development and funding opportunities, as well as local job creation) and benefits to society at large with respect to tackling climate change. Examples were given from communities in Scotland. This role was fulfilled by two people (one for one jury, another for two juries).

The other witness presented the case against wind farms, strongly critiquing wind farms and the way decisions are currently made about them. This was similar to the speakers who presented the case against wind power in the previous session, but with additional focus on the drawbacks of public consultation and community engagement, and the lobbying power of energy companies. Community funding was referred to as bribery. The same witness fulfilled this role for all three juries.

The jurors' questions to the witnesses were wide-ranging, but all three juries asked further questions around the community benefits (funding, jobs), the politics of wind power, and the negative impacts of wind farms. Some questions in this session showed clear frustration at the competing/conflicting information that the jurors were receiving.

Furthermore, at the end of the first Saturday, the jurors were provided with a Handbook prepared by the organizers with oversight by the project Stewarding Board, which contained written information and audiovisual resources, taken from published sources and references relevant to the topic. Jurors also shared their own experiences and knowledge in conversations during structured (e.g. facilitated discussions) and unstructured (e.g. lunch and comfort breaks) sections of the programme.

The second jury day was focused on deliberating to produce recommendations. There were no witnesses present in day 2; however, two of the organizers acted as 'information officers' whereby they could refer back to information in the Handbook or in witnesses' presentations if the jurors requested, or if misunderstanding or misinformation was affecting the course of the deliberation. Jurors set the agenda for day 2 deliberations at the end of the first day. This was revisited and built on at the start of day 2. Much of the deliberation in day 2 occurred in two groups, each supported by a facilitator to identify, develop and agree on shared principles. The principles from the two groups were then brought together, reflected on, reconciled, rephrased or simplified if necessary, and then voted on (to indicate priority issues and level of consensus) in plenary in the second half of the day.

The project was unique because it held three contemporaneous citizens' juries on the same topic and featuring the same process design, thus allowing for robust comparability. The parallel mixed methods research design comprised six data sources including ethnographer notes, evaluator reports, transcriptions, questionnaires, principle statements and other artefacts produced by the participants (e.g. sorting cards, sticky walls). Through their analysis of this dataset, the research team concluded that the juries met to a high standard five core criteria of deliberative quality: uncoerced deliberation, otherregarding deliberation, reasoned deliberation, inclusive and equal participation and unbiased facilitation (see Chapter 5 in Roberts \& Escobar 2015). 
For further detail, see Chapters 4 and 7 of Roberts and Escobar (2015).

\section{Methodology}

Assessment of public deliberation has taken a variety of forms, including empirical studies focusing on the experiences and outcomes of 'the individual, the group and units of discourse' (Black et al. 2011: 326). Therefore, 'consensus on how to operationalize and measure a deliberative process and outcomes has not been reached' (Setälä \& Herne 2014: 71-72). One approach is to ask the participants for their views on the deliberative quality of the discussions they were involved in (Caluwaerts \& Reuchamps 2014), but this method is very subjective and is compromised by social cognitive biases. One of the more frequently used methods employed to assess deliberative quality is the Discourse Quality Index (DQI), which is a theoretically grounded instrument that enables researchers to code speech acts according to key deliberative norms and quantitatively analyse these. It is based on Habermasian communicative rationality and was initially developed to assess parliamentary debates (Jaramillo \& Steiner 2019), but has since been developed and applied to other contexts, including mini-publics (Caluwaerts \& Reuchamps 2014; Elstub \& Pomatto 2018; Gerber 2015; Gerber et al. 2016; Himmelroos 2017; Pedrini 2014). This shows that the general applicability of the DQI and inter-coder reliability tests are used to demonstrate the consistency of the method. It is also a flexible method, so while at present there are no codes for appeals to different types of evidence or expertise, these codes could be added. We chose not to use DQI because, despite its adaptability, it is thought to be a less useful method for assessing deliberative quality of exchanges that 'are spontaneous with frequent, quick, back-andforth discussion, where sometimes an actor intervenes with only a few words' (Jaramillo \& Steiner 2019: 535). Moreover, quantification of deliberative quality has been criticized for adopting an excessively restrictive conception of deliberation, where coders may focus upon 'narrowly defined and measurable indicators that can be found, thus neglecting other aspects less amenable to quantification. The result is serious loss of meaning' (Dahlberg 2004: 31). For example, it is unsuitable for exploring the relationship between reasons offered and conclusions reached (FribergFernos \& Schaffer 2017). Therefore, the DQI reduces assessments of the deliberative quality of reason giving to judgements on 'logical infrastructure or linguistic structure of arguments-an idea that is distant from the concept of communicative rationality underpinning deliberative theories' (Maia et al. 2020: 4). As a result, the DQI reduces the potential of interpretation of deliberative quality to be more sensitive to culture (Mendonça 2015). Interpretive approaches to assessing deliberative quality are more suitable for inquiry into the differences and similarities in argumentation (Maia et al. 2020).

For researchers interested in the ways that meaning is elicited, countered and ultimately shared in deliberative discourse, critical-interpretive methodologies can add to the understandings of what happens in a deliberative process or set of processes. The fields of rhetorical criticism and argumentation studies emphasize a textually focused research methodology that reveals explicit and implicit meanings in the context and text of a discourse. The process of rhetorical criticism, as explained by Jasinski (2001: 256), is an abductive approach to analysis, a 'conceptually oriented criticism' that undertakes 'a back and forth movement between text and the context or concepts that are being investigated simultaneously'. The researchers work inductively, identifying the rhetorical forms and expressions of meaning present in the text, rather than relying on pre-established norms for coding a text. This in turn guides the analysis, with the researcher drawing on particular theories of rhetoric and argumentation for the interpretation of meaning and significance. The rhetorical analysis of deliberation frequently 'focus[es] on the connections among communication, democracy, knowledge and power', and offers insights to how argument impacts 'prudence, practical wisdom and judgment' (Carcasson, Black \& Sink 2010: 4-5). Using this methodology, scholars have studied the argumentation of public deliberation in a variety of formal and informal communication settings, including policy and legislative debates, school boards, community public forums, classrooms and online message boards (Adams 2014; Asen 2015; Asen et al. 2011; Bates \& Lawrence 2014; Drury et al. 2016; Levasseur \& Carlin 2001).

In this project, the concept used to ground the rhetorical analysis was argument theory, particularly the concepts of argumentum ad verecundiam and of experience/local knowledge as evidence. The lead author reviewed transcripts of the second day of the deliberative juries from all three sites. ${ }^{4}$ This session offered the most opportunity for participants to apply and articulate what they identified as important-or unimportant-during deliberation on wind farm development. The jurors may draw on evidence and perspectives shared by witnesses and jurors' on day 1 and any information jurors have read or discussed between day 1 and 2, as well as their own knowledge and experiences. The analysis of the transcripts focused on identifying forms of argumentation present as participants justified their positions and prioritization of recommendations, drawing on argumentation theory to identify forms present in the text. Our analysis demonstrates that the development, engagement and judgement of argumentum ad verecundiam and arguments from local/experiential knowledge differed based on the content area, with notable differences in how health and economics were discussed during the deliberation.

To determine how the different content areas functioned within participants' argumentation, the transcript text was analysed closely to track the development of claims, the use of evidence and subsequent conclusions reached. The analysis was discussed within the research team as a whole, in a process common in collaborative, interpretive analysis (Asen et al. 2013; Bates \& Lawrence 2014). Compared with DQI, which treats deliberation as static (Maia et al. 2020), rhetorical analysis of argumentation enables the consideration of particular interactional exchanges between participants, as well as trends within each jury 
and across the three juries. While no methodology can explore all elements of discourse, rhetorical criticism highlights how different modes of argument function to create meaning, acceptance and contestation within public deliberation.

\section{Analysis}

In a citizens' jury, the deliberative process relies on collaborative communication exchanges between participants to advance the group's reasoning and, ultimately, reach conclusions. Such exchanges rarely involve long speeches, but rather bursts of ideas that layer on top of one another, connecting one participant to the next-or perhaps create divides between them. The wind farm citizens' juries also had facilitators who asked questions or guided the participants to justify a statement, explain a confusing idea, connect two statements or move the group along due to the unavoidable time constraints of the session.

The juries' deliberative task was to determine 'what principles should guide decision making on wind farms and why?' (Roberts \& Escobar 2015: 71). During the deliberation sessions, there was a mix of group interaction and individual reflection/contribution periods, to foster fuller participation from all members. The first exercise, therefore, asked each juror to develop suggestions for topics under which to develop principles. The individual suggestions were placed onto cards, and then clustered collectively on a sticky wall using a consensus-building technique (i.e. metaplan). Facilitators occasionally assisted to group clusters and headings. Each jury site developed their own thematic clusters of priority areas, as shown in Table 3. While the labels used were slightly different, there were commonalities across sites, namely a focus on information/evidence, a focus on strategic planning (Planning and Strategy, Costs and Benefits and Advantages and Disadvantages), and a focus on impact (Impact and Benefits, Visual Impacts and Wildlife Protection, Global Climate Change Context).

After the jurors set their agenda for the day, they then spent an hour and a half focusing on 'Drafting proposals for principles'-a robust session of interactive deliberative communication. In each site, the group subdivided into two smaller groups during the deliberation stage under focus here. To identify across the groups, the citations in this analysis utilizes a numeric system indicating the location and the small group number (e.g. Aberfeldy, Group 1).

The analysis of the six transcripts (two from each site) reveals several insights. First, participants recognized and acknowledged tensions between local experiences on the one hand and expertise on the other. Second, the argumentation from expertise differed in form, based largely around the topic of discussion, namely scientific expertise on questions of health and economic expertise regarding questions of development and planning. In arguments dealing with environmental and health issues, expertise often functioned as de facto reasoning, while in arguments about economics, participants offered multiple forms of evidence through more robust, dialectical exchanges.

\section{Argumentum ad verecundiam and de facto reasoning on environmental and health concerns}

The argumentation and evidence invoked on environmental and health issues prioritized scientific expertise in the deliberative process, sometimes without questioning its relationship to local experiences of the past, and local application of the future. This sort of argument has been criticized as fallacious due to its lack of critical perspective (Woods \& Walton 1974), as well as problematic for democratic engagement (Majdik \& Keith 2011). When expertise goes uncontextualized, the appeals fall victim to inference rather than reasoning, assuming that because experts offer evidence, the information is true and actionable. This runs counter to criticalinterpretive studies that demonstrate that technical knowledge, like lived experience, has value dimensions (Asen 2015: 109; see also Fischer 2000). Participants exhibited de facto reasoning by expressing a high degree of deference to witnesses and invoking a wishful thinking discourse for 'clear information'. However, participants engaged in more robust consideration of argumentum ad verecundiam, when dealing with issues of technology.

When dealing with environmental and health topics, participants across the three jury sites expressed a high measure of deference for expert witnesses. The environmental issues discussed included climate change as well as potential impacts on local ecosystems nearby wind farms; health issues referred to perceived concerns by individuals who lived near wind farms. In invoking and recognizing the evidence presented by these speakers, the jurors tended to invoke environmental and health-based expertise as a pathway towards clearer, unbiased decision making. The Coldstream jury referred to 'impartial views' of scientific evidence about health outcomes and 'clarity of information' as necessary for good decision making (Coldstream, Group 2). An Aberfeldy participant expressed that since the ' $U K$ at the moment is quite good at engineering, so we should take advantage of our ability to be a world leader ... and develop the technology' (Aberfeldy, Group 2). Occasionally some participants

Table 3: Priority areas, as determined by jury site (Roberts \& Escobar 2015: 71).

\begin{tabular}{ll} 
Coldstream & Helensburgh \\
\hline Evidence and Opinions & Lack of Information and Trust \\
Impacts and Benefits & Visual Impacts and Wildlife Protection \\
Costs and Options & Costs and Benefits \\
Planning and Strategy & Energy Alternatives
\end{tabular}

Aberfeldy

Local Control

Advantages and Disadvantages Landscape and Location Global Climate Change Context Strategy and Alternatives for Energy Mix 
expressed scepticism about science, with a few drawing attention to questioning the funding of scientific research. However, participants tended to invoke environmental and health-based expertise as a pathway towards clearer, unbiased decision making.

Participants in all three juries invoked a need for 'clear' information, suggesting a desire for unbiased evidence, or at least uncontradictory evidence. However, the participants did not explicitly discuss what constituted unbiased evidence. This further emphasizes a topoi to look towards de facto appeals to authority in environmental science and health authority. Such an appeal was sought as guidance for the deliberation-but guidance that would clarify the decision-making process as an appeal to dominant, clear thinking without undertaking the difficult process of working through tensions and multiple positions or values. One group in Aberfeldy stressed the need for 'education' and research on the issue, whereas a group in Coldstream repeatedly articulated the importance of 'independence, transparency and available evidence'. Another Aberfeldy group expressed their concern that even after witness presentations, they did not understand the '[potential impact on] health of the local community around wind farms' (Aberfeldy, Group 1). This led to several participants struggling to define what were the health issues and the extent to which wind farms cause health problems to people living nearby:

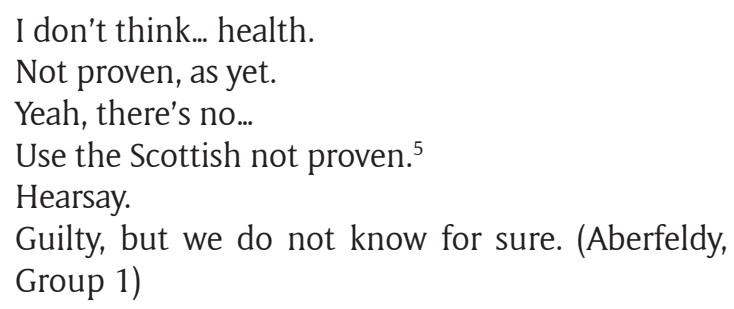

This type of rapid cross-talk amongst participants was found in multiple deliberative groups, and belays an intention to base reasoning on expertise. Several participants continued, even late in the discussion of principles, to call for 'clear, non-biased information of the benefits and negatives' (Aberfeldy, Group 1), and to emphasise that the public needed 'not biased information, but real facts' (Aberfeldy, Group 2). In both of these groups, participants seemed to struggle with the information that had been presented, and desired scientific evidence that the group could discern was reliable. Similarly, participants in Helensburgh and Coldstream expressed the importance of finding out 'who has supported the evidence' to make sure that it was unbiased (Coldstream, Group 2). In stating these concerns, participants drew attention to their desire to use scientific evidence, despite challenges in clarity of the evidence and questions about bias and sourcing. While this desire to move towards facts supports an informed deliberative process, participants did not seem to engage as deeply with types of scientific evidence, instead wishing to rely on what they termed as 'facts' as a de facto argument that would enable better decisionmaking. These numerous appeals for authoritative evidence reinforce the assumption that facts speak for themselves, thus somewhat absolving participants from having to do interpretive and normative work.

Even when a participant tried to contextualize and deepen understanding of the environmental, scientific reasoning in a public problem context, other participants returned to the familiar argumentum ad verecundiam of needing 'clear' knowledge. For example, one participant echoed the framing from the anti-wind witness presentation, which was then criticized and rejected by the larger group (Aberfeldy, Group 1). Other people in the group then expressed their desire for "clear, easy to understand information that's not a certain side' for issues such as wind farm development (Aberfeldy, Group 1). Even when arguments that invoked the pro- or antiperspectives, or attempted to review the benefits and tradeoffs of scientific knowledge appeared, participants still sought environmental evidence as de facto decisionmaking guidance.

One exception to the de facto reliance on scientific expertise was when science was framed as technology, rather than in terms of environmental or health factors. In such cases, expertise was seen as reliant on past data, with a recognition that future decisions would need to adapt or apply the data. This is a more robust and critical argument form, since participants contextualized the data in a dialectic format:

Because if you are looking at a 25-year time span... you know, a computer 25 years ago wasn't as big as it is now so we may not be discussing a 200-foot wind farm, you know?

[Facilitator] Okay. Can you capture that slightly more so that the other group understand when they read that? ...

It seems to be about the unknowns of technological advance. You can't really predict a radical change.

Can I just say maybe there's a linkage between something [Participant Name] said earlier on about the timescale of, you know, if we're only relying on past evidence and trying to understand what happens in the future.

It's the future unknown.

[participants discuss the 'future unknown' in terms of how the evidence and results of wind farm energy may change over time]

And I think one of the alternatives is that you've got to look at what will they do in 2030? We don't know if there's going to be nuclear power. So you don't know what the alternatives will be in the future. (Coldstream, Group 1)

Here, participants recognized that while there may be compelling evidence about the efficiency of wind farm technology for delivering power, they also saw wind farms as an infrastructure investment, and that evidence about their efficiency may change over time. Later, participants from the same group returned to this theme, suggesting that it was important to recognize "new alternatives in the future that you could come up with by the time 
they've built the wind farm' and also to come up with clear 'target[s]' for measuring efficiency of the technology. This contextualization of scientific evidence, embodying a more deliberative perspective, was much more present in the framing of science as technology rather than health or climate.

It is worth noting that sometimes participants rejected scientific expertise in favour of a de facto acceptance of their personal or localized preferences. For example, in Aberfeldy, there were a few participants who stridently proclaimed they were 'against' wind farms in the past, and were still against them in the present discussion. Similarly, in Coldstream, some participants seemed to question scientific evidence around climate change more readily than the rest of the group, maintaining this rejection even in later remarks made in the deliberation. In such moments, arguments functioned more antagonistically, dismissing qualified expertise and the group's collective reasoning. While limited to only a few participants, the examples mentioned here serve as further evidence that participants tended to accept or reject scientific expertise de facto rather than through robust public reasoning.

\section{Dialectical engagement on economic concerns}

In contrast to arguments about environmental and health expertise relying primarily on de facto argumentation, economic and social scientific expertise was more often invoked and contextualized by participants in their deliberations. In particular, participants frequently related economic evidence to their local knowledge and experiences. Such usage enabled deeper deliberation, connecting the technical and personal spheres of argument to further deliberation in the public sphere (Goodnight 1982). In particular, participants examined forms of evidence such as statistics and cost estimates, connecting this expertise to localized contexts for a more prudential, deliberative judgement.

A central economic discussion amongst the groups was about how an increase in wind power might benefit local communities and citizens. Participants used evidence relating to economic expertise to discuss the added value of wind farms in a particular locality. For example, they noted the importance of statistics to ground the discussion in contextual factors such as looking 'into people's income to help more, i.e. the elderly' (Helensburgh, Group 1). On economic issues, therefore, the use of statistics was often combined with concern for individuals or groups in the community, reflecting how local knowledge fits into the public issue. These discussions clearly placed evidence in the context of interpretive and normative work.

In Helensburgh, a participant shared their perspectives about the 'true cost' of wind farms, noting that 'information on everything for it should be made available', including the cost of building the wind farm, 'how much have they paid for that land', 'how much is it going to cost for each individual thing' and ultimately, 'where is that money coming from'. The group then began to discuss that evidence in reference to the particular local community and ongoing planning process, with other participants suggesting that there needed to be a clear discussion of 'hidden costs'. One participant then offered the suggestion to have a sort of 'itemized billing' to localize the expenses of wind farms for communities and compare that against savings in electricity cost; others engaged this idea. The group affirmed that 'we should be getting' and 'we should be seeing' this type of itemization (Helensburgh, Group 2). This exchange demonstrated the group's efforts to connect arguments from economic expertise into the local realm. Furthermore, in launching this sort of reasoning exercise, participants first identified that there was economic evidence around how wind farms could provide savings to local communities in terms of power costs, but that those savings had to be measured against the real cost of developing the farms. Participants elaborated this sort of dialectic during the deliberation:

We see the cost, we see the benefit.

We should be getting that information.

This much of your bill came from wind farms.

Yeah, why not?

This is why it's cost you more.

Why not? Because then, you know? I mean, getting out with the argument of renewables against other energy sources, you're going to see the true cost and benefit to yourself and your house and your bills and also to us as a community (Helensburgh, Group 2).

When weighing the consideration of how wind farms could impact communities, the jurors engaged expertise on broad, economic principles and then applied this outside expertise to their local knowledge and beliefs of potential impact on communities. For example, in Coldstream, one group deliberated in a similar fashion about the potential costs and benefits, and ultimately articulated a principle that stated, 'Accurate and clear financial costs should be collated and communicated on a range of renewable energy options' (Coldstream, Group 2). In Aberfeldy, one group suggested that the fiscal benefit of wind farms needed to benefit 'a population rather than a person or company', after one participant noted that it seemed unfair for any individual-especially a politician-to benefit from leasing their land for a wind farm when everyone's landscape was impacted. The group later noted that the whole 'local economy' might be impacted 'in terms of tourism', which added evidence from local knowledge as to why economic advantages to the cost of electricity might not be a straightforward benefit to a specific community (Aberfeldy, Group 2). Contrary to environmental and health-based expertise, nearly every group actively engaged the argumentum ad verecundiam of economic expertise. This is the sort of 'dialectical engagement' suggested by Woods and Walton (1974), with the rhetorical function of bringing expertise into dialogue with local understandings of the issue. Such engagement also functions to foster exploration of different values and perspectives, and to acknowledge that on many issues there may not be a clear set of 'facts' or a single source of evidence. This rhetoric therefore upholds deliberative norms for re-examining expertise 
in light of specific contexts to come to a reasoned and prudent understanding of evidence (Fischer 2000; Majdik \& Keith 2011).

At multiple deliberation sites, jury groups robustly questioned the economic expertise around the cost and benefits of wind power in relation to the particular locations. Several members spent time questioning the statistics that were previously presented, with some participants expressing that 'you can make your facts and figures mean anything' and that 'creative accountants' might alter figures. These challenges took place despite efforts by the Information Officer to provide reassurances about the quality of the evidence, for instance by reminding the group that any figures or facts used in the information sessions "have got the source" (Coldstream, Group 2). Another group in Aberfeldy had a multi-interlocutor disagreement about cost-benefit analyses in terms of economic impact (as judged by government officials) and local decision-making. One participant suggested that even if the cost-benefit would yield a positive value, if local people were against wind farms, then they should not be built:

As in, if $82 \%$ of the people in this town said 'No, I do not want that wind farm' but higher up the government 'Oh, but that could make us eightytwo thousand pounds' ... That our opinions (other voice: Exactly) matter more than making money (Aberfeldy, Group 1).

While not everyone in the group agreed with this assertion, the group exchanged reasons about the expert, economic evidence for wind farms versus having local opinion 'heard and that [local opinion] cannot be overridden' (Aberfeldy, Group 1). These examples demonstrate a marked difference from the use of environmental and health-based evidence, which a few groups challenged as problematic only when funded by special interests. In contrast, economic evidence was more broadly contested by multiple groups as open to challenge and interpretation.

\section{Discussion}

There has already been a good deal of research on deliberative quality in mini-publics, but there are three key limitations to this body of work. Firstly, while there are exceptions (Elstub \& Pomatto 2018), it has primarily focused on deliberative polls (Gerber et al. 2016; Siu 2017). Deliberative polls have a larger number of participants than most other mini-publics and they do not encourage participants to strive for agreement. Since both of these factors could affect deliberative quality, we need further research on smaller mini-publics that try and reconcile different views, such as citizens' juries. Secondly, the existing research on deliberative quality in mini-publics has been based primarily on data gathered through content analysis (Caluwaerts \& Reuchamps 2014; Gerber 2015; Gerber et al. 2016; Himmelroos 2017; Pedrini 2014) or participant evaluation (Caluwaerts \& Reuchamps 2014), both of which have interpretive limitations. Thirdly, and most importantly, the existing research has largely overlooked the influence of expert witnesses, and the differing types of evidence that they provide, on deliberative quality. To address these gaps, we conducted a rhetorical analysis of the transcripts from three citizens' juries in Scotland that deliberated onshore wind farm development.

In this multisite deliberation, argumentation followed similar patterns despite differences between local experiences and contextualization. The analysis here suggests that in the rhetoric of the deliberation on wind farms, environmental and health expertise was more likely to be accepted de facto. This was not the case for technical and socioeconomic evidence, where expertise was more readily connected to local knowledge, experiences and values. Participants received sometimes conflicting evidence on all these topics on day 1 but engaged differently with evidence according to the subject. This indicates a separation of argumentation between technical and public spheres around the topic of wind farms.

Problems regarding de facto appeals are particularly relevant for evidence on impact assessment. When jurors appealed to-or expressed desire for-de facto expertise and evidence on the effect of wind farms on health and environment, this indicates that they perceive the issues to be a 'tame or benign' scientific problem (Rittel \& Webber 1973: 160) which can, through study, have a clear outcome. Such a view of scientific issues is problematic; a suite of uncertainties complicates many fields of scientific enquiry, leading to differences in evidence intended to clarify facts or values (Fischhoff \& Davis 2014). Impact assessment is particularly challenging in this regard; assessment processes include many uncertainties (Tenney, Kværner \& Gjerstad 2006) and rely on value judgements to define the scope of study and deliberate the significance and relative importance of impacts and, ultimately, whether negative impacts are acceptable or not (Ehrlich \& Ross 2015; Wilkins 2003). Assessment frameworks tend to be technocratic and so do not reflect citizens' values, leading to problematic assessment outcomes (Stolp et al. 2002). The jurors' appeals for de facto evidence may disregard contextual factors that are critical to understanding impacts, especially on communities.

The absence of engaged rhetoric on these topics during deliberation may stem from the relative lack of attention paid to these subjects in the information phase. The questions posed to expert witnesses across all sessions on the first Saturday primarily focused on technical clarifications, social and economic factors and the decision-making process for wind farms, with fewer questions around environment and health (Roberts \& Escobar 2015). Furthermore, the Juror's Handbook provided some resources on noise and health, but not on environmental effects. Witnesses speaking against wind farms presented evidence on negative local impacts of wind farms on health and wildlife both in sessions 2 and 3 , whereas witnesses speaking in favour of wind farms did not present evidence on such impacts (beyond the role of renewable energy in tackling climate change). These 'pro' witnesses could be perceived to have vested business interests (Roberts et al. 2020), which may have affected how the jurors engaged with any counter evidence they 
provided in the plenary discussion. Collectively, therefore, the relative lack of evidence and scrutiny thereof may indicate that the portfolio of evidence on the effect of wind farms on environment and health was weak and/ or prevented jurors from engaging deeply with different evidence dimensions on these topics. Finally, it could simply be that the jurors engaged more confidently with dimensions where they had more personal, local experiences to draw on, such as technology, infrastructure and economics, as opposed to apparently removed complex evidence on the environmental or health impacts of wind farms.

Such findings may translate beyond the topic of wind farms to other socioscientific issues. For deliberative design, therefore, citizens need adequate opportunities to develop capacity and confidence to engage, question, critique and connect with the relevant types of evidence and expertise to enhance deliberative quality. Otherwise, the risk is that participants may be susceptible to the disempowering effects of having to accept appeals to expertise at face value, rather than on the basis of reasoned argumentation. Organizers of public deliberation may also need to create sessions explicitly reserved for participants to deliberate and develop a shared understanding about what they deem as 'unbiased', 'clear', expert information. This will further enable citizens to grapple with the implications of argumentum ad verecundiam in the context of local experiences and knowledge, thus elevating deliberative discourse. It also demonstrates the need for mini-publics to include critical thinking sessions that build participants' capacity to assess what counts as evidence, the criteria for 'good' evidence and how to weigh competing evidence based on different methods and epistemologies (Roberts et al. 2020).

In addition, when considering public deliberations about energy-and in particular, wind farms-organizers may need to consider that arguments from expertise are so often deployed in a de facto manner that this might even encourage a sense of distrust amongst citizens. While scientific expertise should play a leading role in discussions about environmental policy, climate change and health outcomes, science communicators must also recognize the rhetorical dimensions of their engagement and discourse. Explicitly positioning scientific facts alongside social implications and policy concerns would lead to a more ethical mode of deliberative problemsolving. This would also encourage citizens to deliberate more deeply through argumentation that meaningfully combines scientific and local/experiential knowledge. This is an important point for mini-public designers to consider when deciding on their evidence sessions and how best to involve different types of witnesses. In particular, it suggests deliberative quality would be improved if they use panels of experts, with differing types of expertise, so that the participants can compare and contrast their arguments directly alongside each other (Roberts et al. 2020).

Further research is required on the different uses of argumentation and different types of evidence in mini-publics, and how this affects deliberative quality.
Moreover, research on how different types of argument play out in the broader public sphere and how different actors engage in reasoning remain important dimensions for future studies of public deliberation.

\section{Data Accessibility Statement}

The research from the citizens' juries on wind farms project, including transcripts of deliberations, are available by contacting O.E. (oliver.escobar@ed.ac.uk).

\section{Notes \\ ${ }^{1}$ See Roberts et al. (2020). \\ ${ }^{2}$ See https://whatworksscotland.ac.uk/topics/mini- publics/ for more information. \\ ${ }^{3}$ Scotland 2011 Census (Area Profiles) published by the National Records of Scotland. Available at: https:// www.scotlandscensus.gov.uk. \\ ${ }^{4}$ Proceedings in day 1 were not transcribed. \\ ${ }^{5}$ This makes reference to the existence of 3 possible verdicts in the Scottish criminal justice system: guilty, not guilty and not proven.}

\section{Acknowledgements}

The team of organisers and researchers was drawn from the University of Edinburgh, University of Strathclyde, University of Glasgow, Queen Margaret University, University of West of Scotland and Robert Gordon University. The authors of this article would like to thank all organisers, researchers, participants, Stewarding Board members and witnesses who made the project possible, and in particular the Project Manager, Ragne Low. In addition, the IASH-School of Social and Political Science Research Fellowship at the Institute for Advanced Studies in the Humanities, University of Edinburgh, supported Sara Drury's research and analysis for this article. Previous versions of this project have been presented at the Deliberative Quality of Communication Conference at the University of Manheim, Germany, and a Colloquium Lecture at the Centre for Deliberative Democracy and Global Governance, University of Canberra, Australia. The authors thank participants at these events for their constructive comments.

\section{Funding Information}

The project was funded by ClimateXChange, the Scottish Government's Centre for Expertise on Climate Change, coordinated by the Edinburgh Centre for Carbon Innovation. S.A.M.D.'s contribution was supported by the IASH-SSPS Research Fellowship, Institute for Advanced Studies in the Humanities, University of Edinburgh. O.E.'s contribution was supported by What Works Scotland (ESRC ES/M003922/1).

\section{Competing Interests}

The authors have no competing interests to declare.

\section{Author Contributions}

S.A.M.D., S.E., O.E. and J.J.R. contributed to the design and implementation of the research, to the analysis of the results and to the writing of the manuscript. 


\section{References}

Adams, B. E. (2014). Reason-giving in deliberative forums. Journal of Public Deliberation, 10(2), Article 6. DOI: https://doi.org/10.16997/jdd.208

Asen, R. (2015). Democracy, deliberation, and education. State College, PA: The Pennsylvania State University. DOI: https://doi.org/10.1515/9780271073163

Asen, R., \& Gent, W. (2019). Reconsidering symbolic use: A situational model of the use of research evidence in polarised legislative hearings. Evidence \& Policy, 15(4), 525-541. DOI: https://doi.org/10.1332/1744264 18X15378681033440

Asen, R., Gurke, D., Conners, P., Solomon, R., \& Gumm, E. (2013). Research evidence and school board deliberations: Lessons from three Wisconsin school board districts. Educational Policy, 27(1), 33-63. DOI: https://doi.org/10.1177/0895904811429291

Asen, R., Gurke, D., Solomon, R., Conners, P., \& Gumm, E. (2011). "The research says": Definitions and uses of a key policy term in federal law and local school board deliberations. Argumentation and Advocacy, 47(4), 195-213. DOI: https://doi.org/10.1080/00028533.2 011.11821747

Black, L. W., Burkhalter, S., Gastil, J., \& StromerGalley, J. (2011). Methods for analyzing and measuring group deliberation. In E. P. Bucy \& R. L. Holbert (Eds.), The sourcebook for political communication research: Methods, measures, and analytical techniques (pp. 323-345). London: Routledge. DOI: https://doi. org/10.4324/9780203938669-29

Bates, B. R., \& Lawrence, W. Y. (2014). Mommy groups as sites for deliberation in everyday speech. Journal of Public Deliberation, 10(2), Article 7. DOI: https://doi. org/10.16997/jdd.209

Bauer, M. W., Allum, N., \& Miller, S. (2007). What can we learn from 25 years of PUS survey research? Liberating and expanding the agenda. Public Understanding of Science, 16(1), 79-95. DOI: https:// doi.org/10.1177/0963662506071287

Bohman, J. (1999). Democracy as inquiry, inquiry as democratic: Pragmatism, social science, and the cognitive division of labor. American Journal of Political Science, 43(2), 590-607. DOI: https://doi. org/10.2307/2991808

Böker, M., \& Elstub, S. (2015). The possibility of critical mini-publics: Realpolitik and normative cycles in democratic theory. Representation, 51(1), 125-144. DOI: https://doi.org/10.1080/00344893.2015.10262 05

Burkhalter, S., Gastil, J., \& Kelshaw, T. (2002). A conceptual definition and theoretical model of public deliberation in small face-to-face groups. Communication Theory, 12(4), 398-422. DOI: https:// doi.org/10.1111/j.1468-2885.2002.tb00276.x

Caluwaerts, D., \& Reuchamps, M.(2014). Does intergroup deliberation lead to intergroup appreciation? Evidence from two deliberative experiments in Belgium. Politics, 34(2), 101-115. DOI: https://doi.org/10.1111/14679256.12043
Carcasson, M., Black, L. W., \& Sink, E. S. (2010). Communication studies and deliberative democracy: Current contributions and future possibilities. Journal of Public Deliberation, 6(1), Article 8. DOI: https://doi. org/10.16997/jdd.96

Condit, C. M., \& Bates, B. R. (2009). Rhetorical methods of applied communication research. In L. R. Frey \& K. N. Cissna (Eds.), Routledge handbook of applied communication research (pp. 106-128). New York: Routledge.

Dahlberg, L. (2004). Net-public sphere research: Beyond the "first phase". Javnost, 11(1), 27-44. DOI: https:// doi.org/10.1080/13183222.2004.11008845

Dietz, T. (2013). Bringing values and deliberation to science communication. PNAS, 110(Suppl 3), 14081-14087. DOI: https://doi.org/10.1073/pnas.1212740110

Drury, S. A. M., Andre, D., Goddard, S., \& Wentzel, J. (2016). Assessing deliberative pedagogy: Using a learning outcomes rubric to assess tradeoffs and tensions. Journal of Public Deliberation, 12(1), Article 5. DOI: https://doi.org/10.16997/jdd.245

Dryzek, J. (2014). Institutions for the anthropocene: Governance in a changing earth system. British Journal of Political Science, 46(4), 937-956. DOI: https://doi. org/10.1017/S0007123414000453

Elstub, S. (2014). Mini-publics: Issues and cases. In S. Elstub \& P. McLaverty (Eds.), Deliberative democracy: Issues and cases. Edinburgh, UK: Edinburgh University Press.

Elstub, S., \& Pomatto, G. (2018). Mini-publics and deliberative constitutionalism. In J. King, $\mathrm{H}$. Kong, \& R. Levy (Eds.), The Cambridge handbook of deliberative constitutionalism. Cambridge, UK: Cambridge University Press. DOI: https://doi. org/10.1017/9781108289474.023

Escobar, 0. (2014). Transformative practices: The political work of public engagement practitioners. (PhD Thesis, University of Edinburgh Edinburgh, UK). Open Access: https://www.era.lib.ed.ac.uk/handle/1842/9915

Escobar, O., \& Elstub, S. (2017). Forms of mini-publics: An introduction to deliberative innovations in democratic practice. Research and Development Note 4. newDemocracy Foundation. Open Access: https:// www.newdemocracy.com.au/2017/05/08/forms-ofmini-publics/

Ercan, S. A., Hendriks, C. M., \& Boswell, J. (2017). Studying public deliberation after the systemic turn: The crucial role for interpretive research. Policy \& Politics, 45(2), 195-212. DOI: https://doi.org/10.1332 /030557315X14502713105886

Ehrlich, A., \& Ross, W. (2015). The significance spectrum and EIA significance determinations. Impact Assessment and Project Appraisal, 33(2), 87-97. DOI: https://doi.org/10.1080/14615517.2014.981023

Fischer, F.(2000). Citizens, experts, and the environment:The politics oflocal knowledge. Durham, NC: Duke University Press. DOI: https://doi.org/10.1515/9780822380283

Fischhoff, B., \& Davis, A. L. (2014). Communicating scientific uncertainty. Proceedings of the National 
Academy of Sciences of the United States of America, 111(Suppl 4), 13664-13671. DOI: https://doi. org/10.1073/pnas.1317504111

Friberg-Fernos, H., \& Schaffer, J. K. (2017). Assessing the epistemic quality of democratic decision-making in terms of adequate support for conclusions. Social Epistemology, 31(3), 251-265. DOI: https://doi. org/10.2139/ssrn.2419954

Gastil, J. (2017). Designing public deliberation at the intersection of science and public policy. In $\mathrm{K} . \mathrm{H}$. Jamieson, D. Kahan, \& D. A. Scheufele (Eds.), The Oxford handbook of science communication (pp. 233-242). Oxford, UK: Oxford University Press. DOI: https://doi. org/10.1093/oxfordhb/9780190497620.013.26

Gastil, J., \& Knobloch, K. R. (2020). Hope for democracy: Bringing reason back into politics. Oxford, UK: Oxford University Press. DOI: https://doi.org/10.1093/ oso/9780190084523.001.0001

Gerber, M. (2015). Equal partners in dialogue? Participation equality in a transnational deliberative poll (Europolis). Political Studies, 63(1), 110-130. DOI: https://doi.org/10.1111/1467-9248.12183

Gerber, M., Bächtiger, A., Shikano, S., Reber, S., \& Rohr, S. (2016). Deliberative abilities and influence in a transnational deliberative poll (EuroPolis). British Journal of Political Science, 48(4), 1093-1118. DOI: https://doi.org/10.1017/S0007123416000144

Goodin, R. E., \& Niemeyer, S. (2003). When does deliberation begin? Internal reflection versus discussion in deliberative democracy. Political Studies, 51(4), 627-649. DOI: https://doi.org/10.1111/j.00323217.2003.00450.x

Goodnight, T. (2005). Science and technology controversy: A rationale for inquiry. Argumentation and Advocacy, 42, 26-29. DOI: https://doi.org/10.1080/00028533.2 005.11821636

Goodnight, T. (1982). The personal, technical, and public spheres of argument: A speculative inquiry into the art of public deliberation. Journal of the American Forensic Association, 18, 214-227. DOI: https://doi.org/10.108 0/00028533.1982.11951221

Goodwin, J. (2011). Accounting for the appeal to the authority of experts. Argumentation, 25, 285-296. DOI: https://doi.org/10.1007/s10503-011-9219-6

Google Maps. (2020). Scotland (map view). Retrieved from https://goo.gl/maps/rFb5HAnZcPjK81La8.

Gross, A. (1994). The roles of rhetoric in the public understanding of science. Public Understanding of Science,3(1),3-23.DOI:https://doi.org/10.1088/0963$6625 / 3 / 1 / 001$

Head, B. W. (2008). Wicked problems in public policy. Public Policy, 3(2), 101-118.

Himmelroos, S. (2017). Discourse quality in deliberative citizen forums: A comparison of four deliberative minipublics. Journal of Public Deliberation, 13(1), Article 3. DOI: https://doi.org/10.16997/jdd.269

Jaramillo, M. C., \& Steiner, J. (2019). From discourse quality index to deliberative transformative moments. In S. Elstub \& O. Escobar (Eds.), Handbook of democratic innovation and governance (pp. 527539). Cheltenham, UK: Edward Elgar Publishing. DOI: https://doi.org/10.4337/9781786433862.00048

Jasinski, J. (2001). The status of theory and method in rhetorical criticism. Western Journal of Communication, 65(3), 249-270. DOI: https://doi. org/10.1080/10570310109374705

Karpowitz, C., Mendelberg, T., \& Shaker, L. (2012). Gender inequality in deliberative participation. American Political Science Review, 106(3), 533-547. DOI: https://doi.org/10.1017/S0003055412000329

Levasseur, D. G., \& Carlin, D. B. (2001). Egocentric argument and the public sphere: Citizen deliberations on public policy and policymakers. Rhetoric \& Public Affairs, 4(3), 407-431. DOI: https://doi.org/10.1353/ rap.2001.0045

Levin, K., Cashore, B., Bernstein, S., \& Auld, G. (2012). Overcoming the tragedy of super wicked problems: Constraining our future selves to ameliorate global climate change. Policy Science, 45, 123-152. DOI: https://doi.org/10.1007/s11077-012-9151-0

Lukianova, E., Tolochin, I., Fuji Johnson, G., \& Knobloch, K. R. (2019). Varieties and effects of emotional content in public deliberation: A comparative analysis of advocate arguments at a citizens' initiative review. Journal of Language and Politics, 18(3), 441-462. DOI: https://doi.org/10.1075/jlp.14013.luk

Macnaughten, P., Kearnes, M. B., \& Wynne, B. (2005). Nanotechnology, governance, and public deliberation: What role for social sciences? Science Communication, 27(2), 268-291. DOI: https://doi. org/10.1177/1075547005281531

Maia, R. C. M., Cal, D., Barga, J., \& Crepdale, N. J. B. (2020). Which types of reason-giving and storytelling are good for deliberation? Assessing the discussion dynamics in legislative and citizen forums. European Political Science Review, 12(2), 113-132. DOI: https:// doi.org/10.1017/S1755773919000328

Majdik, Z., \& Keith, W. M. (2011). Expertise as argument: Authority, democracy, and problem-solving. Argumentation, 25, 371-384. DOI: https://doi. org/10.1007/s10503-011-9221-z

Mansbridge, J., Hartz-Karp, J., Amengual, M., \& Gastil, J. (2006). Norms of deliberation: An inductive study. Journal of Public Deliberation, 2(1), Article 7. DOI: https://doi.org/10.16997/jdd.35

Mendonça, R. F. (2015) Assessing some measures of online deliberation. Brazilian Political Science Review, 9(3), 88-115. DOI: https://doi.org/10.1590/198138212015000300021

Nabatchi, T. (2012). An introduction to deliberative civic engagement. In T. Nabatchi, J. Gastil, G. M. Weiksner, \& M. Leighninger (Eds.), Democracy in motion (pp. 3-17). Oxford, UK: Oxford University Press. DOI: https://doi.org/10.1093/acprof: oso/9780199899265.003.0001

Pedrini, S. (2014). Deliberative capacity in the political and civic sphere. Swiss Political Science Review, 20(2), 263-286. DOI: https://doi.org/10.1111/spsr.12074 
Renn, 0. (2004). The challenge of integrating deliberation and expertise: Participation and discourse in risk management. In T. McDaniels \& M. J. Small (Eds.), Risk analysis and society: An interdisciplinary characterization of the field (pp. 289-366). Cambridge, UK: Cambridge University Press. DOI: https://doi. org/10.1017/CBO9780511814662.009

Rittel, H. W. J., \& Webber, M. M. (1973). Dilemmas in a general theory of planning. Policy Sciences, 4, 155169. DOI: https://doi.org/10.1007/BF01405730

Roberts, J., \& Escobar, O. (2015, May). Involving communities in deliberation: A study of 3 citizens' juries on onshore wind farms in Scotland. [Public report]. Retrieved from https://www.climatexchange. org.uk/media/1438/citizens_juries_-_full_report.pdf

Roberts, J. J., Lightbody, R., Low, R., \& Elstub, S. (2020). Deliberating evidence in deliberation: Scrutinising the role of witness and evidence in mini-publics, a case study. Policy Sciences, 53, 3-32. DOI: https://doi. org/10.1007/s11077-019-09367-x

Setälä, M., \& Herne, K. (2014). Normative theory and experimental research in the study of deliberative mini-publics. In K. Grönlund, A. Bächtiger, \& M. Setälä (Eds.), Deliberative mini-publics: Involving citizens in the democratic process (pp. 59-75). Colchester: ECPR.

Siu, A. (2017). Deliberation and the challenge of inequality. Daedalus, 146(3), 119-128. DOI: https:// doi.org/10.1162/DAED_a_00451

Sprain, L., Carcasson, M., \& Merolla, A. (2014). Utilizing "on tap" experts in deliberative forums: implications for design. Journal of Applied Communication Research, 42(2), 150-167. DOI: https://doi.org/10.1080/00909 882.2013.859292

Steffensmeier, T., \& Schenck-Hamlin, W. (2008). Argument quality in public deliberations.
Argumentation \&Advocacy, 45(1), 21-36. DOI: https:// doi.org/10.1080/00028533.2008.11821693

Stolp, A., Groen, W., Van Vliet, J., \& Vanclay, F. (2002). Citizen values assessment: Incorporating citizens' value judgements in environmental impact assessment. Impact Assessment and Project Appraisal, 20(1), 11-23. DOI: https://doi. org/10.3152/147154602781766852

Tenney, A., Kværner, J., \& Gjerstad, K. I. (2006). Uncertainty in environmental impact assessment predictions: The need for better communication and more transparency. Impact Assessment and Project Appraisal, 24(1), 45-56. DOI: https://doi. org/10.3152/147154606781765345

Von Wienterfeldt, D. (2013). Bridging the gap between science and decision making. PNAS, 110(Suppl 3), 14055-14061. DOI: https://doi.org/10.1073/ pnas. 1213532110

Walton, D. N. (1997). Appeal to expert opinion: Arguments from authority. University Park, PA: Pennsylvania State University Press.

Walton, D. (2008). Informal logic: A pragmatic approach. Cambridge, UK: Cambridge University Press.

Wilkins, H. (2003). The need for subjectivity in EIA: Discourse as a tool for sustainable development. Environmental Impact Assessment Review, 23(4), 401-414. DOI: https://doi.org/10.1016/S01959255(03)00044-1

Woods, J., \& Walton, D. (1974). Argumentum ad verecundiam. Philosophy and Rhetoric, 7, 135-153. Retrieved from http://www.jstor.org/stable/40237194

Zenker, F. (2011). Experts and bias: When is interestbased objection to expert argumentation sound? Argumentation, 25, 355-370. DOI: https://doi. org/10.1007/s10503-011-9226-7

How to cite this article: Drury, S. A. M., Elstub, S., Escobar, O., \& Roberts, J. J. (2021). Deliberative Quality and Expertise: Uses of Evidence in Citizens' Juries on Wind Farms. Journal of Deliberative Democracy, 7(2), pp. 31-44. DOI: https://doi.org/10.16997/ jdd.986

Submitted: 13 September $2019 \quad$ Accepted: 02 June $2020 \quad$ Published: 22 November 2021

Copyright: () 2021 The Author(s). This is an open-access article distributed under the terms of the Creative Commons Attribution 4.0 International License (CC-BY 4.0), which permits unrestricted use, distribution, and reproduction in any medium, provided the original author and source are credited. See http://creativecommons.org/licenses/by/4.0/. 